\title{
28 Research Suare \\ Opioid use in Older Orthopedic Rehabilitation Inpatients: A Retrospective Study
}

\section{Aaron Jason Bilek}

Sinai Health

\section{Stephanie Cullen}

Queen's University

\section{Carolyn Michelle Tan}

University of Toronto

\section{Qixuan Li}

Biostatistics Research Unit, University of Toronto

\section{Ella Huszti}

Biostatistics Research Unit, University of Toronto

Richard E Norman ( $\nabla$ richard.norman@sinaihealth.ca )

Sinai Health

\section{Research Article}

Keywords: geriatrics, rehabilitation, opioids, pain, post-operative care, orthopedics

Posted Date: December 16th, 2021

DOI: https://doi.org/10.21203/rs.3.rs-1118268/v1

License: (c) (i) This work is licensed under a Creative Commons Attribution 4.0 International License.

Read Full License 


\section{Abstract}

Background: While there is much evidence about pain management for orthopedic patients in the immediate perioperative setting, little is known about how opioids are used during inpatient rehabilitation in the days and weeks that follow, particularly in older adults. A safe upper limit of 50 oral morphine equivalents (OME) is frequently cited in guidelines. This study's objective is to characterize the use of opioids in an older adult population undergoing orthopedic rehabilitation.

Methods: This is a retrospective observational study of adults aged $\geq 50$ years old admitted for orthopedic rehabilitation between November 2019 and June 2021 at an academic rehabilitation hospital in Toronto, Canada. Acute care admissions preceding rehabilitation were for either a surgical or nonsurgical orthopedic indication. Participants were divided into opioid-naïve individuals who received opioids, opioid-naïve individuals who did not receive opioids, and pre-existing chronic users of opioids. Demographic, clinical, and medication administration data were collected through the electronic health record and manual chart review. Average daily opioid dose for the first seven days of each stay was characterized using OME. Linear regression was used to assess for variables independently associated with opioid dose.

Results: A total of 643 patients undergoing orthopedic rehabilitation were included: 125 (19.4\%) involved chronic opioid users, 416 (64.7\%) were opioid-naïve patients who received opioids, and 102 (15.9\%) were opioid-naïve patients who did not receive opioids, with median age respectively of 72,79 , and 83 . Median daily OME over the first week for chronic users was 30.3 and for opioid-naïve users was 6.9. Opioid dose was significantly positively associated with reported pain as defined by day 3 pain score and knee replacement; it was inversely associated with admission for a non-surgical indication and age.

Conclusions: Opioids are frequently but heterogeneously used in older adults undergoing orthopedic rehabilitation. Median OME use in this cohort of older adults was substantially lower than the $50 \mathrm{OME}$ threshold suggested in guidelines. Dedicated guidance for opioid use is warranted for this unique patient population.

\section{Introduction:}

Opioids are frequently used in the post-operative period as part of a comprehensive analgesia strategy (1). Of surgeries performed in Canada, orthopedic surgeries are among the most common (2). New opioid prescriptions originating in this setting have been shown to be an important contributor to the ongoing opioid crisis (3). Characteristics of the initial prescribing episode such as high dose, long duration, and use of long-acting formulations are strongly associated with the development of chronic use (4). Older adults, who are highly represented in the orthopedic population (5), are not immune to this phenomenon (6). They are also more vulnerable to developing opioid-related adverse drug events, such as changes in cognition, respiratory depression, falls, urinary retention, and constipation $(7,8)$. 
Findings such as these have prompted the publication of guidelines delineating best practices for opioid prescribing, including recommendations for limiting the daily dose to less than 50 oral morphine equivalents (OME) per day due to substantial risk of harms above this level (9-12). Detailed recommendations for pain management and opioid stewardship exist for the spectrum of perioperative care, from the preoperative phase through to discharge from acute care $(13,14)$. However, guidance is lacking for patients discharged to a post-acute setting such as inpatient orthopedic rehabilitation (IOR), who comprise around $15 \%$ of patients undergoing orthopedic surgery (15). Many of these patients are older and frailer than those who return home directly from acute care (16-18). Therefore, post-acute settings such as orthopedic rehabilitation are highly relevant for the pain management of complex, older post-surgical patients (19), and may be an ideal opportunity to deprescribe opioids and optimize the analgesic regimen prior to discharge home.

Unfortunately, little research exists about opioid prescribing in IOR patients. While some studies have reported on patterns of opioid use for older adults in the immediate postoperative period (20-21), we were not able to identify any such reports for post-acute patients, or for IOR in particular. We therefore conducted this retrospective study to investigate characteristics of patients in IOR and their patterns of opioid use.

\section{Methods:}

\section{Setting:}

This is a single-center retrospective study of opioid use in IOR patients admitted to Bridgepoint Active Healthcare (BAH), an academic rehabilitation hospital which is part of Sinai Health in Toronto, Canada. Prescribers at $\mathrm{BAH}$ are typically family medicine-trained hospitalists experienced in treating the orthopedic rehabilitation population. Care team members included medical specialists, nurses, physiotherapists, occupational therapists, and other allied health providers.

\section{Rehabilitation activities:}

The primary goal of inpatient rehabilitation was for the patient to regain function and mobility sufficient to safely return to the home environment. Patients in the high-intensity rehabilitation stream usually performed daily rehabilitation activities for a length of stay of two to three weeks. Patients with an anticipated poorer activity tolerance or barriers to rehabilitation were admitted under a low-intensity rehabilitation stream with therapy distributed over a longer length of stay.

\section{Patient population:}

We included all patients aged 50 and above participating in orthopedic rehabilitation between November 2019 and June 2021. The focus of the study was on older adults (65+) but a younger cohort (50-64) was included to maximize generalizability as these individuals also receive clinical care on the units under study. 
Patient encounters were excluded if:

1. The patient was admitted for a non-orthopedic indication.

2. The indication was orthopedic but involved malignancy such as sarcoma or metastases.

3. The patient had fractures in more than two body regions, typically as a result of traumatic injury.

4. The patient was well enough to be discharged to the community in less than seven days, since this was the period selected for assessment of opioid use and follow-up pain scores.

5. The patient was not admitted directly from acute care (e.g. they had spent some weeks in convalescence prior to orthopedic rehabilitation admission due to non-weight bearing status.)

6. The admission was part of a chain of admissions for the same patient and for the same indication (e.g. a patient requiring a series of surgeries with intervals in rehabilitation between them). In such cases, only the first encounter in the chain was included.

7. The patient was a chronic user of high-potency opioids including intravenous drugs, methadone, buprenorphine, or fentanyl.

In cases of uncertainty, inclusion was adjudicated by the senior team members (R.N. and A.B.).

\section{Data collection:}

Data was collected by a combination of automated reporting from the electronic health record and manual review of electronic charts. A.B., R.N., S.C., and C.T. performed manual data extraction using a standardized review algorithm. An adjudication procedure was established to address discrepancies in coding.

See Supplement 1 for full details of the data collection. In brief, this included: demographic information; Charlson Comorbidity Index (22); health conditions associated with likelihood of conversion to chronic opioid use $(1,23)$; baseline functional status for basic activities of daily living; the original indication for surgical or non-surgical treatment; the referring hospital where care was provided; and length of stay (LOS) in the referring hospital prior to arrival at rehabilitation. The following measures were recorded on admission to rehabilitation: EGFR (by the CKD-EPI equation) (24); Functional Independence Measure (FIM), a measure of mobility and function widely used in the rehabilitation setting to document a patient's progress (psychometric properties have been described in detail by Cournan) (25); and highest pain score on day 3 at rehabilitation (shown to be a useful initial time point for predicting the effect of pain on rehabilitation outcomes) (26).

Opioid use was measured as the type and dose of opioid administered to each patient averaged over the first seven days in rehabilitation, with doses converted to oral morphine equivalents (OME) to facilitate comparison. Complications commonly associated with opioids were also monitored.

Outcomes included LOS at rehabilitation, maximal pain score on day 7, FIM score on discharge, FIM change and FIM efficiency (FIM change divided by length of stay), and proportion discharged to a community setting at the end of their rehabilitation stay. Patients requiring an acute hospital stay of less than 72 hours were considered to have had a program interruption and continued in the study upon return 
to rehabilitation, while patients absent from rehabilitation for more than 72 hours were considered to have been discharged to acute care (in line with definitions from the American Uniform Data System for Medical Rehabilitation) (27).

\section{Statistical analysis:}

Patients were divided into three groups of interest: $(A)$ chronic opioid users (those with a home opioid medication listed on the admission pharmacy report, or with a listed diagnosis of chronic opioid use), (B) opioid-naïve patients who did receive opioids during the orthopedic rehabilitation admission, and (C) opioid-naïve patients who did not receive any opioids during the orthopedic rehabilitation admission.

The three groups were compared using the non-parametric Kruskal-Wallis test for continuous variables, while the Chi-square test was used for categorical variables.

The motivation of this research was to better understand the use of opioids in naïve users with an eye for prevention of de novo chronic opioid use in these patients. Higher initial opioid dose has been previously linked to the development of chronic use (4). We therefore developed univariable and multivariable linear regression models for opioid-naïve patients to test for associations between opioid dose and the measured factors described above. In addition to age and sex, we included BMI (28), pre-existing dementia $(29,30)$, and pre-existing psychiatric or substance-use disorder $(23)$ regardless of statistical significance because of previous association of these factors with opioid use. Backward stepwise selection and interaction checking was used to develop a parsimonious model. An additional linear regression model was developed to investigate how covariates of the primary model might be reflected in reported day 3 pain score.

\section{Results:}

We reviewed a total of 947 patient encounters of which 304 were excluded: 78 were not admitted for an orthopedic indication, 72 were for multiple visits by the same patient, 68 were cancer-related, 32 were for fractures in more than two body areas, 23 were not admitted directly from acute care, 11 were discharged to the community in less than 7 days, 10 were for individuals who previous used high-potency opioids, and 9 where the patient returned to acute care before assessments could be completed.

Of 643 included patient encounters, 125 (19.4\%) involved chronic opioid users, 416 (64.7\%) were opioidnaïve patients who received opioids during orthopedic rehabilitation, and 102 (15.9\%) were opioid-naïve patients who did not receive opioids during orthopedic rehabilitation. Table 1 presents the patient characteristics for these three groupings. Chronic users were younger, had a higher BMI, and had a higher rate of psychiatric comorbidity. They were typically admitted for surgery and had a high proportion of elective joint replacements. Opioid-naïve users were older, had a lower BMI, and had a lower rate of psychiatric comorbidity. They were slightly less likely to have been operated on, with substantially less elective surgery. Non-users of opioids were older, had lower BMIs, and had a higher rate of dementia and 
baseline functional impairment. They were less likely to have undergone surgery, with only a minority of these surgeries being elective in nature.

Table 1

Patient Characteristics

\begin{tabular}{|c|c|c|c|c|}
\hline & $\begin{array}{l}\text { Chronic } \\
\text { user }\end{array}$ & $\begin{array}{l}\text { Opioid } \\
\text { naive }\end{array}$ & $\begin{array}{l}\text { Non- } \\
\text { opioid } \\
\text { user }\end{array}$ & $p$ \\
\hline$n$ & 125 & 416 & 102 & \\
\hline Age (median (IQR)) & $\begin{array}{l}72(65, \\
76)\end{array}$ & $\begin{array}{l}79(71, \\
87)\end{array}$ & $\begin{array}{l}83(73, \\
90)\end{array}$ & $<0.001$ \\
\hline Female Sex (\%) & $78(62.4)$ & $293(70.4)$ & $64(62.7)$ & 0.124 \\
\hline BMI (median (IQR)) & $\begin{array}{l}27.6(23.4, \\
33.7)\end{array}$ & $\begin{array}{l}25.3(22.1 \\
29.7)\end{array}$ & $\begin{array}{l}22.5(19.8 \\
26.5)\end{array}$ & $<0.001$ \\
\hline Dementia (\%) & $1(0.8)$ & $22(5.3)$ & $15(14.7)$ & $<0.001$ \\
\hline Anxiety or Depression (\%) & $49(39.2)$ & $108(26.0)$ & $22(21.6)$ & 0.005 \\
\hline History of Substance Use (\%) & $14(11.2)$ & $28(6.7)$ & $14(13.7)$ & 0.044 \\
\hline Charlson Comorbidity Index (median (IQR)) & $3(3,4)$ & $4(3,5)$ & $4(3,5)$ & 0.003 \\
\hline $\begin{array}{l}\text { Independent in All Basic Activities of Daily Living } \\
(\%)\end{array}$ & $101(80.8)$ & $341(82.6)$ & $73(71.6)$ & 0.043 \\
\hline Admitted Following Surgery (\%) & $113(90.4)$ & $337(81.0)$ & 64 (62.7) & $<0.001$ \\
\hline Elective Surgery (\%) & $78(62.4)$ & $162(38.9)$ & $16(15.7)$ & $<0.001$ \\
\hline Admitted Following Non-Surgical Treatment & $14(11.2)$ & $79(19.0)$ & $38(37.3)$ & $<0.001$ \\
\hline Surgery Type (\%) & & & & $<0.001$ \\
\hline Hip Fracture & $21(16.8)$ & $147(35.3)$ & $38(37.3)$ & \\
\hline Hip Replacement & $44(35.2)$ & $76(18.3)$ & $10(9.8)$ & \\
\hline Knee Replacement & $30(24.0)$ & $75(18.0)$ & $5(4.9)$ & \\
\hline Other Surgery & $16(12.8)$ & $39(9.4)$ & $11(10.8)$ & \\
\hline $\begin{array}{l}\text { Length of Stay in Acute Care Prior to } \\
\text { Rehabilitation in Days (median (IQR)) }\end{array}$ & $4(2,7)$ & $4(3,7)$ & $5(3,8)$ & 0.286 \\
\hline EGFR (median (IQR)) & $\begin{array}{l}87(63 \\
100)\end{array}$ & $\begin{array}{l}83(61, \\
96)\end{array}$ & $\begin{array}{l}80(64, \\
90)\end{array}$ & 0.029 \\
\hline FIM on Admission (median (IQR)) & $\begin{array}{l}80(75, \\
86)\end{array}$ & $\begin{array}{l}80(74 \\
85)\end{array}$ & $\begin{array}{l}80(75, \\
89)\end{array}$ & 0.583 \\
\hline
\end{tabular}


Table 2summarizes patient outcomes. Chronic users had a higher median opioid dose than naïve-users (30.3 mg vs $6.9 \mathrm{mg}$ OME daily) and used long-acting formulations more frequently. The distribution of opioid medications and formulations used are detailed in Supplement 2. Median lengths of stay were slightly less in chronic users, with similar functional and discharge outcomes between groups. Maximal pain on day 3 was highest in chronic users and lowest in non-users. Pain did not materially change from day 3 to 7 in any group. Opioid-related side-effects were distributed similarly among the groups, with constipation being the most common. Nausea was more common in chronic users versus naïve users, with non-users reporting the least nausea. Severe adverse events including acute kidney injury, injurious fall, and respiratory complications were rare and without significant intergroup differences (data not shown). Only $11(1.7 \%)$ patients experienced a program interruption and $42(6.5 \%)$ patients returned to acute care, with only 2 of these complications deemed potentially related to opioid use on retrospective chart review. 
Table 2

Outcomes

\begin{tabular}{|c|c|c|c|c|}
\hline & $\begin{array}{l}\text { Chronic } \\
\text { user }\end{array}$ & $\begin{array}{l}\text { Opioid } \\
\text { naive }\end{array}$ & $\begin{array}{l}\text { Non-opioid } \\
\text { user }\end{array}$ & $\mathbf{p}$ \\
\hline $\mathrm{n}$ & 125 & 416 & 102 & \\
\hline $\begin{array}{l}\text { Median Opioid Use Daily in mg OME } \\
\text { (median (IQR)) }\end{array}$ & $\begin{array}{l}30.3(7.4 \\
72.0)\end{array}$ & $\begin{array}{l}6.9(2.4 \\
16.1)\end{array}$ & $\mathrm{n} / \mathrm{a}$ & $<0.001$ \\
\hline $\begin{array}{l}\text { Proportion Receiving Long Acting Opioid } \\
\text { Formulations (\%) }\end{array}$ & $45(36.0)$ & $42(10.1)$ & $\mathrm{n} / \mathrm{a}$ & $<0.001$ \\
\hline $\begin{array}{l}\text { Maximum Pain Reported on Day } 3 \text { (median } \\
(\text { IQR)) }\end{array}$ & $5(3,7)$ & $4(2,6)$ & $3(2,4)$ & $<0.001$ \\
\hline $\begin{array}{l}\text { Maximum Pain Reported on Day } 7 \text { (median } \\
\text { (IQR)) }\end{array}$ & $5(3,7)$ & $4(2,6)$ & $2(0,4)$ & $<0.001$ \\
\hline \multicolumn{5}{|l|}{ Opioid-Related Complications } \\
\hline Urinary Retention (\%) & $8(6.4)$ & $37(8.9)$ & $5(4.9)$ & 0.328 \\
\hline Constipation (\%) & $71(56.8)$ & $238(57.2)$ & $53(52.0)$ & 0.627 \\
\hline Confusion or Delirium (\%) & $9(7.2)$ & $20(4.8)$ & $6(5.9)$ & 0.573 \\
\hline Nausea (\%) & $40(32.0)$ & $94(22.6)$ & $19(18.6)$ & 0.039 \\
\hline $\begin{array}{l}\text { Rehabilitation Length of Stay in Days } \\
\text { (median (IQR)) }\end{array}$ & $20(12,28)$ & $22(14,35)$ & $23(14,35)$ & 0.109 \\
\hline FIM on Discharge (median (IQR)) & $\begin{array}{l}111(107 \\
115)\end{array}$ & $\begin{array}{l}110(103, \\
114)\end{array}$ & $\begin{array}{l}111(106 \\
115)\end{array}$ & 0.031 \\
\hline FIM Change (mean (SD)) & $29(9)$ & $28(9)$ & $27(8)$ & 0.371 \\
\hline FIM Efficiency (median (IQR)) & $\begin{array}{l}1.75(1.27 \\
2.20)\end{array}$ & $\begin{array}{l}1.46(1.08 \\
2.07)\end{array}$ & $\begin{array}{l}1.43(0.95 \\
2.00)\end{array}$ & 0.044 \\
\hline Discharged to a Community Setting (\%) & $111(88.8)$ & 388 (93.3) & 89 (87.3) & 0.075 \\
\hline
\end{tabular}

Univariable regression results for factors correlating with opioid dose are shown in Supplement 3. Results of multivariable regression modeling for opioid dose can be seen in Table 3. In the final multivariable model, age was inversely correlated with amount of opioid administered. Reported pain, as defined by day 3 pain score, was associated with increased opioid use. Knee replacement was associated with increased opioid use while admission for a non-surgical indication was associated with lower opioid requirements.

Univariable and multivariable regression modeling results examining the factors contributing to day 3 pain scores can be seen in Supplement 4 . The multivariable model identified underlying dementia as 
being negatively associated with reported pain and a history of psychiatric illness as being positively associated with reported pain.

A separate tabulation examining the amount of daily opioid administered over the first week, specifically to opioid naïve users (i.e. excluding chronic users and non-opioid users) by age showed that those aged 50-64 received a median of $19.4 \mathrm{mg}$ daily, $65-74$ received $12.6 \mathrm{mg}, 75-84$ received $6.0 \mathrm{mg}$ and $85+$ received $3.4 \mathrm{mg}$.

Table 3

Multivariable Regression Associations with Opioid Dose in Oral Morphine Equivalents (OME) (Final Model)

\begin{tabular}{|c|c|c|}
\hline & Coefficients (Cl) & $\mathrm{p}$ \\
\hline Age & $-2.348(-3.251,-1.437)$ & $<0.0001$ \\
\hline Female Sex & $0.832(-18.1,24.2) 0.938$ & 0.938 \\
\hline BMI & $1.121(-0.425,2.691)$ & 0.157 \\
\hline Dementia & $-17.9(-44.3,21)$ & 0.32 \\
\hline Psychiatric Disorder & $8.884(-13.7,37.3)$ & 0.473 \\
\hline Elective Surgery & $40.7(-7.94,115)$ & 0.115 \\
\hline Admitted Following Non-Surgical Treatment & $-36.3(-50.9,-17.4)$ & $<0.001$ \\
\hline Hip Replacement & $8.141(-33.8,76.6)$ & 0.755 \\
\hline Knee Replacement & $71.2(4.039,182)$ & 0.035 \\
\hline Other Surgery & $12.8(-22.4,64.1)$ & 0.527 \\
\hline Maximum Pain Reported on Day 3 & $19.2(14.6,24)$ & $<0.0001$ \\
\hline
\end{tabular}

\section{Discussion:}

Many challenges exist in orthopedic rehabilitation when it comes to opioid stewardship, including significant variability in indications for admission, patient heterogeneity and variability in prescribing practices between referring hospitals. Furthermore, existing guidelines do not provide recommendations specific to managing opioid use in IOR patients. Notably, advice is often focused on the immediate postoperative period, with little guidance for the days and weeks that follow.

Our data reveals different profiles of IOR patients with disparate patterns of opioid use. Chronic users were on average younger and with a higher BMI, had a higher rate of prior psychiatric comorbidity and were typically admitted following elective joint replacement. They consumed 4.5 -fold the amount of 
opioid when compared to the naïve users. Opioid-naïve users tended to be older and had a lower proportion of elective surgeries. Non-users of opioids were the oldest group and had an even lower proportion of elective surgeries. These patients had more markers of frailty such as lower baseline functional independence and a higher rate of dementia, which likely impacted their perceived candidacy for both surgery and opioids.

Prior work has shown that higher initial opioid dose is related to the development of chronic use (4). Therefore, knowledge of what factors are associated with prescribing high initial doses of opioids in orthopedic rehabilitation is central to minimizing the number of patients who leave orthopedic rehabilitation with a new opioid prescription. The regression model for opioid administration demonstrated that day 3 pain scores, reason for admission, and age were independently associated with opioid dose. The correlation of pain scores with opioid dose is unsurprising. In our cohort, knee replacement was associated with higher opioid dose but not with higher pain. It has previously been observed that knee replacement is more painful than hip replacement and is associated with higher opioid consumption in the immediate post-operative period (31-32). One interpretation is that providers may be pre-emptively administering larger doses of opioids in anticipation of pain in this group. Conversely to knee replacement, rehabilitation following a non-operative reason for orthopedic admission (e.g. pelvic or vertebral compression fracture) was associated with lower opioid use. It may be that patient factors such as older age or frailty predominate in this group, particularly given their overrepresentation in the cohort that did not receive opioid therapy (Table 1). This observation may also reflect the fact that these individuals likely bypass protocolized perioperative analgesia orders or assessment by pain specialists given that they did not undergo surgery.

The inverse relationship of opioid administered with age, particularly in opioid-naïve individuals, is of clinical relevance both for frontline care and when developing guidance for care of these patients. Guidelines often cite a cautious upper limit of 50 morphine equivalents daily (9-12). Our data demonstrate that opioid-naïve older patients in IOR typically require far less opioid: of patients aged 75+ in our cohort who used opioids, only $19 \%$ used $>10 \mathrm{mg}$ OME and only $8.5 \%$ used $>20 \mathrm{mg}$ OME per day (data not shown). While opioid pharmacokinetics are largely similar to younger patients, pharmacodynamic changes have been demonstrated in older patients such that an 80-year-old person needs $50 \%$ less opioid than a 40 -year-old to achieve the same analgesic effect (33). Together this would support a downward adjustment of the expected dosing window for older adults undergoing orthopedic rehabilitation. Prescriber discretion may also be playing a role when faced with offering higher opioid doses to individuals perceived to be more vulnerable to adverse effects. The vast majority of older adults in our cohort also did not require long-acting opioids, resonating with calls to eschew use of these formulations due to higher risk of adverse events and dependence (34).

While psychiatric comorbidity $(23)$ and cognitive impairment $(29,30)$ have previously been linked to opioid use, they were not found to be significant in our model of opioid use (Table 3 ). One potential explanation is that their impact may be mediated through pain reporting or experience; indeed, the regression model for day 3 pain revealed these factors to be independently associated. Psychiatric 
comorbidity is a well-known risk factor for the development of chronic post-surgical pain (35). The inverse association of dementia with reported pain could potentially reflect difficulty with self-reporting of pain in people with moderate-to-severe cognitive impairment or perhaps may reflect undertreatment (29, 30 ). While characterization of pain was not the focus of this work, these observations do support the idea that opioid prescribing should be tailored with a holistic understanding of an individual patient's needs, particularly in older adults who are more likely to have pre-existing neuropsychiatric comorbidity.

This study had several limitations. We could not quantify opioid use in the acute setting prior to orthopedic rehabilitation nor baseline opioid use prior to hospitalization (beyond presence or absence of a pre-existing opioid prescription), both factors potentially pertinent to the analysis. The pain scores used here were collected as part of clinical care and so may reflect variability of individual provider practice; we do not have data on interrater reliability specific to our institution. The generalizability of these findings may also be limited because this is a single-centre study.

\section{Conclusions And Implications:}

Our research provides new data on how opioids are used in an older orthopedic rehabilitation population and which factors may predict opioid use. We emphasize that older patients may require lower doses of opioid than typically described in guidelines, although orthopedic rehabilitation patients also have heterogeneous clinical profiles which may impact their opioid use patterns. Prescriber and institutional practices for the use of opioids should recognize this heterogeneity, for example by having guidance specific to the management of pain in older adults. This work also highlights that opioid use as part of a pain management strategy in orthopedic rehabilitation is distinct from pain management in the immediate perioperative setting and deserves individualized attention.

\section{Abbreviations}

$\mathrm{BAH}$ - Bridgepoint Active Healthcare; BMI - body mass index; EGFR - estimated glomerular filtration rate; FIM - functional independence measure; IOR - inpatient orthopedic rehabilitation; OME - oral morphine equivalent.

\section{Declarations}

\section{Ethics approval and consent to participate:}

the protocol for this research was approved by the Mount Sinai Research Ethics Board, and was conducted in accordance with the Declaration of Helsinki. Informed consent was waived by the Mount Sinai Hospital Research Ethics Board due to the retrospective and aggregated nature of the data used in the analysis. 


\section{Consent for publication:}

Not applicable

\section{Availability of data and material:}

The datasets generated and/or analysed during the current study are not publicly available due to limitations imposed by the Mount Sinai Research Ethics Board, but are available from the corresponding author on reasonable request.

\section{Competing interests:}

none of the authors has any competing interests to declare

\section{Funding sources:}

Sinai Health Department of Medicine Research Committee

\section{Author's contributions:}

All authors meet criteria for authorship as stated in the Uniform Requirements for Manuscripts Submitted to Biomedical Journals (see contributions below). No conflicts of interest exist for any of the authors.

- Study concept and design: Aaron Jason Bilek and Richard E Norman

- Acquisition of data: Aaron Jason Bilek, Stephanie Cullen, Carolyn Michelle Tan, Richard Norman

- Analysis and data interpretation: Aaron Jason Bilek, Richard E Norman, Qixuan Li, Ella Huszti

- Drafting of the manuscript: Aaron Jason Bilek and Richard E Norman

- Critical revision of the manuscript for important intellectual content: Aaron Jason Bilek, Stephanie Cullen, Carolyn Michelle Tan, Richard E Norman, Ella Huszti

\section{Acknowledgements:}

We would like to thank the Sinai Health Geriatrics Summer Scholars Program for their support in enabling this work.

\section{References}


1. Chou R, Gordon DB, Leon-Casasola OA de, Rosenberg JM, Bickler S, Brennan T, et al. Management of Postoperative Pain: A Clinical Practice Guideline From the American Pain Society, the American Society of Regional Anesthesia and Pain Medicine, and the American Society of Anesthesiologists' Committee on Regional Anesthesia, Executive Committee, and Administrative Council. J Pain. 2016 Feb 1;17(2):131-57. http://dx.doi.org/10.1016/j.jpain.2015.12.008

2. Canadian Institute for Health Information. Hospital Stays in Canada. [cited 2021 Aug 10]; Available from: https://www.cihi.ca/en/hospital-stays-in-canada

3. Bai J-W, Bao J, Bhatia A, Chan VWS. A perioperative approach to the opioid crisis. CMAJ. 2018 Oct 1;190(39):E1151-2. http://dx.doi.org/10.1503/cmaj.180801

4. Shah A, Hayes CJ, Martin BC. Characteristics of Initial Prescription Episodes and Likelihood of LongTerm Opioid Use - United States, 2006-2015. MMWR Morb Mortal Wkly Rep. 2017 Mar 17;66(10):265-9. http://dx.doi.org/10.15585/mmwr.mm6610a1

5. Canadian Institute for Health Information. Canadian Joint Replacement Registry. [cited 2021 Aug 14]; Available from: https://www.cihi.ca/en/canadian-joint-replacement-registry-cjrr

6. Torchia MT, Munson J, Tosteson TD, Tosteson ANA, Wang Q, McDonough CM, et al. Patterns of Opioid Use in the 12 Months Following Geriatric Fragility Fractures: A Population-Based Cohort Study. J Am Med Dir Assoc. 2019 Mar 1;20(3):298-304. http://dx.doi.org/10.1016/j.jamda.2018.09.024

7. Naples JG, Gellad WF, Hanlon JT. Managing Pain in Older Adults: The Role of Opioid Analgesics. Clin Geriatr Med. 2016 Nov;32(4):725-35. http://dx.doi.org/10.1016/j.cger.2016.06.006

8. O'Neil CK, Hanlon JT, Marcum ZA. Adverse Effects of Analgesics Commonly Used by Older Adults with Osteoarthritis: Focus on Non-Opioid and Opioid Analgesics. Am J Geriatr Pharmacother. 2012 Dec;10(6):331-42. http://dx.doi.org/10.1016/j.amjopharm.2012.09.004

9. Hegmann KT, Weiss MS, Bowden K, Branco F, DuBrueler K, Els C, et al. ACOEM practice guidelines: opioids for treatment of acute, subacute, chronic, and postoperative pain. J Occup Environ Med. 2014 Dec;56(12):e143-159. http://dx.doi.org/10.1097/JOM.0000000000000352

10. The Washington State Agency Medical Directors' Group. Interagency Guideline on Prescribing Opioids for Pain. [cited 2021 Aug 10]; Available from: https://www.agencymeddirectors.wa.gov/Files/2015AMDGOpioidGuideline.pdf

11. Busse J. The 2017 Canadian Guideline for Opioids for Chronic Non-Cancer Pain. Cancer Pain. 2017;105.

12. Dowell D, Haegerich TM, Chou R. CDC Guideline for Prescribing Opioids for Chronic Pain-United States, 2016. JAMA. 2016 Apr 19;315(15):1624. http://dx.doi.org/10.1001/jama.2016.1464

13. Hyland SJ, Brockhaus KK, Vincent WR, Spence NZ, Lucki MM, Howkins MJ, et al. Perioperative Pain Management and Opioid Stewardship: A Practical Guide. Healthcare. 2021 Mar;9(3):333. http://dx.doi.org/10.3390/healthcare9030333

14. Beverly A, Kaye AD, Ljungqvist $O$, Urman RD. Essential Elements of Multimodal Analgesia in Enhanced Recovery After Surgery (ERAS) Guidelines. Anesthesiol Clin. 2017 Jun;35(2):e115-43. 
http://dx.doi.org/10.1016/j.anclin.2017.01.018

15. Ong KL, Lotke PA, Lau E, Manley MT, Kurtz SM. Prevalence and Costs of Rehabilitation and Physical Therapy After Primary TJA. J Arthroplasty. 2015 Jul 1;30(7):1121-6.

http://dx.doi.org/10.1016/j.arth.2015.02.030

16. Oldmeadow LB, McBurney H, Robertson VJ. Predicting risk of extended inpatient rehabilitation after hip or knee arthroplasty. J Arthroplasty. 2003 Sep;18(6):775-9. http://dx.doi.org/10.1016/s08835403(03)00151-7

17. Gholson JJ, Pugely AJ, Bedard NA, Duchman KR, Anthony CA, Callaghan JJ. Can We Predict Discharge Status After Total Joint Arthroplasty? A Calculator to Predict Home Discharge. J Arthroplasty. 2016 Dec 1;31(12):2705-9. http://dx.doi.org/10.1016/j.arth.2016.08.010

18. Canadian Institute for Health Information. Demographic Characteristics of Inpatient Rehabilitation Clients. [cited 2021 Aug 11]; Available from: https://www.cihi.ca/en/demographic-characteristics-ofinpatient-rehabilitation-clients

19. Rodriguez JC, Dzierzewski JM, Fung CH, Jouldjian S, Josephson KR, Mitchell MN, et al. Association Between Pain and Functional Independence in Older Adults During and After Admission to Rehabilitation After an Acute Illness or Injury. J Am Geriatr Soc. 2015;63(11):2275-81. http://dx.doi.org/10.1111/jgs.13792

20. Petre BM, Roxbury CR, McCallum JR, DeFontes KW, Belkoff SM, Mears SC. Pain Reporting, Opiate Dosing, and the Adverse Effects of Opiates After Hip or Knee Replacement in Patients 60 Years Old or Older. Geriatr Orthop Surg Rehabil. 2012 Mar;3(1):3-7. http://dx.doi.org/10.1177/2151458511432758

21. Dagenais-Beaulé V, Tourigny J-F, Papillon-Ferland L. Opioid Use and Pain Control in the Elderly After Elective or Urgent Orthopaedic Surgery: A Retrospective Cohort Study. Clin Drug Investig. 2019 Mar;39(3):301-8. http://dx.doi.org/10.1007/s40261-018-00744-7

22. Charlson ME, Pompei P, Ales KL, MacKenzie CR. A new method of classifying prognostic comorbidity in longitudinal studies: development and validation. J Chronic Dis. 1987;40(5):373-83. http://dx.doi.org/10.1016/0021-9681(87)90171-8

23. Furlan $A D$, Hassan S, Famiyeh I-M, Wang W, Dhanju J. Long-term opioid use after discharge from inpatient musculoskeletal rehabilitation. J Rehabil Med. 2016 Apr 28;48(5):464-8. http://dx.doi.org/10.2340/16501977-2080

24. Levey AS, Stevens LA, Schmid CH, Zhang YL, Castro AF, Feldman HI, et al. A new equation to estimate glomerular filtration rate. Ann Intern Med. 2009 May 5;150(9):604-12. http://dx.doi.org/10.7326/0003-4819-150-9-200905050-00006

25. Cournan M. Use of the Functional Independence Measure for Outcomes Measurement in Acute Inpatient Rehabilitation. Rehabil Nurs. 2011;36(3):111-7. http://dx.doi.org/10.1002/j.20487940.2011.tb00075.x

26. Sahota B, Alavinia SM, Kumbhare D, Sangha H, Flannery J, Furlan A. A Retrospective Study of the Association between Pain Intensity and Opioid Use with Length of Stay during Musculoskeletal 
Inpatient Rehabilitation after Primary Knee and Hip Arthroplasty. PM\&R. 2020;12(5):462-9. http://dx.doi.org/10.1002/pmrj.12250

27. Galloway RV, Granger CV, Karmarkar AM, Graham JE, Deutsch A, Niewczyk P, et al. The Uniform Data System for Medical Rehabilitation Report of Patients with Debility Discharged from Inpatient Rehabilitation Programs in 2000 - 2010. Am J Phys Med Rehabil Assoc Acad Physiatr. 2013 Jan;92(1):14-27. http://dx.doi.org/10.1097/PHM.0b013e31827441bc

28. Belcaid I, Eipe N. Perioperative Pain Management in Morbid Obesity. Drugs. 2019 Jul 1;79(11):116375. http://dx.doi.org/10.1007/s40265-019-01156-3

29. Achterberg WP, Cameron ID, Bauer JM, Schols JM. Geriatric Rehabilitation-State of the Art and Future Priorities. J Am Med Dir Assoc. 2019 Apr;20(4):396-8.

http://dx.doi.org/10.1016/j.jamda.2019.02.014

30. Scherder E, Herr K, Pickering G, Gibson S, Benedetti F, Lautenbacher S. Pain in dementia. PAIN. 2009 Oct;145(3):276-8. http://dx.doi.org/10.1016/j.pain.2009.04.007

31. Pinto PR, Mclntyre T, Araújo-Soares V, Costa P, Ferrero R, Almeida A. A comparison of predictors and intensity of acute postsurgical pain in patients undergoing total hip and knee arthroplasty. J Pain Res. 2017 May 9;10:1087-98. http://dx.doi.org/10.2147/JPR.S126467

32. Pang WW, Hsu TC, Tung CC, Hung CP, Chang DP, Huang MH. Is total knee replacement more painful than total hip replacement? Acta Anaesthesiol Sin. 2000 Sep;38(3):143-8.

33. Gupta DK, Avram MJ. Rational Opioid Dosing in the Elderly: Dose and Dosing Interval When Initiating Opioid Therapy. Clin Pharmacol Ther. 2012;91(2):339-43. http://dx.doi.org/10.1038/clpt.2011.307

34. Levy N, Mills P. Controlled-release opioids cause harm and should be avoided in management of postoperative pain in opioid naïve patients. $\mathrm{Br} J$ Anaesth. 2019 Jun 1;122(6):e86-90. http://dx.doi.org/10.1016/j.bja.2018.09.005

35. Weinrib AZ, Azam MA, Birnie KA, Burns LC, Clarke H, Katz J. The psychology of chronic post-surgical pain: new frontiers in risk factor identification, prevention and management. $\mathrm{Br} \mathrm{J}$ Pain. 2017 Nov;11(4):169-77. http://dx.doi.org/10.1177/2049463717720636

\section{Supplementary Files}

This is a list of supplementary files associated with this preprint. Click to download.

- SupplementaryMaterial.docx 